College of Medicine, University of Basrah, Department of Medicine, Iraq

\section{Correspondence:}

Dr. Abdulameer Abdulbari.

College of Medicine, University of Basrah, Department of Medicine, Iraq

E mail: drabd7@gmail.com

\title{
Clinical Evaluation of Efficacy and Safety of Combined Topical Timolol and Oral Propranolol in Children with Infantile Hemangioma
}

\author{
Muntaha Abdul Hadi Mathkoor, Khalil I. Al- Hamdi, Abdulameer Abdulbari
}

\section{A B S T R A C T}

Objective: To evaluate the efficacy and safety of combined topical timolol and oral propranolol in treatment of infantile hemangioma.

Patients and methods: This prospective study was conducted in Basra teaching hospital in Basra, Iraq, where a total of 23 infants with 34 lesions of different types of hemangioma were included. All lesions were in proliferation phase. The infants' ages were less than one year. They were treated with topical timolol solution $0.5 \%$ combined with oral propranolol in a period of 12 weeks (8-16 weeks). The response to treatment was evaluated clinically by using hemangioma score and Visual analogue scale. All infants followed 4-12 months after cessation of drugs.

Results: By using hemangioma score system; the combined therapy showed that, 28 (82.4\%) lesions showed excellent response, two (5.9\%) showed good response, four (11.8\%) showed fair response and none of the lesions showed poor response at end of 16 weeks. At the end of 4 months superficial hemangioma showed $100 \%$ reduction in their score, while the ulcerative hemangioma showed $94.7 \%$ reduction in their score while mixed hemangioma showed only $76.7 \%$ reduction in their scores. Complete resolution occurred in $50 \%$ of lesions after 4 months of treatment. Neither included infants developed serious side effects nor, any of the regressed hemangioma recur during the follow up.

Conclusion: Combined topical Timolol $0.5 \%$ solution and oral propranolol seems to be a welltolerated, safe treatment option with a good to excellent responses. The most responsive type of hemangioma to this combination are the superficial and ulcerative types.

Key Words: Hemangioma, children, treatment, timolol, propranolol, outcome

\section{INTRODUCTION}

Infantile hemangiomas are benign proliferations of endothelial tissue that represent the most common tumors arising in the neonatal period, they demonstrate a typical growth pattern characterized by early proliferation followed by gradual, spontaneous involution [1]. Many complications may occur in IH such as ulceration, airway obstruction, visual disturbance, cosmetic disfigurement, and systemic involvement, so the treatment of $\mathrm{IH}$ is frequently indicated in many cases [2]. Many treatments were used for IH but none of them is FDA approved except propranolol [3], despite of this truth, the proper dosage, mode of administration and long-term outcome still not standardized. The major obstacles to treatment with systemic propranolol was the long duration, so introduction of other modality of treatment with systemic propranolol may shorten the duration of treatment of $\mathrm{IH}$, ultimately improve the outcome. Topical timolol which is $4-10$ times as potent as propranolol [4], added to systemic propranolol in treatment of $\mathrm{IH}$ in this study to achieve the above-mentioned issue.

\section{PATIENTS AND METHODS}

\section{Study Design}

A prospective clinical therapeutic study was conducted in Dermatology department at Basra Teaching hospital during the period from
Accepted: 20.03 .2018

DOI: $10.5799 /$ jcei.413049 
August 2015 to the end of January 2017, where 23 infants with infantile hemangiomas were enrolled in this study; 22 of them were females and one was male. Their ages were less than one year. These infants presented with 34 lesions of hemangioma at different sites of their bodies.

\section{Inclusion criteria}

Every infant with infantile hemangioma and their ages less than one year.

\section{Exclusion criteria}

Any infant who has bronchial asthma, heart failure, heart block, diabetes mellitus, sinus bradycardia, hypotension, known allergy to beta-blockers, history of hypoglycemia, syndrome hemangioma and those, who took other modalities of treatment for infantile hemangioma.

\section{Evaluation of the infants before treatment}

All infant's parents were interviewed, and a detailed history of each patients was taken regarding age, sex, onset of hemangioma, location and size of lesions, previous cardiopulmonary disease, history of bronchospasm and history of hypoglycemia.

Physical examination was done by cardiologist for cardiopulmonary system. Heart rate, blood pressure, respiratory rate and body weight measured in each visit. Blood glucose, electrocardiogram, and abdominal ultrasound to assess hepatic hemangioma (for multiple hemangioma $\geq 5$ ) are conducted for all infants.

All patient's parents were informed about the natural history of hemangioma, possible options of treatments and side effects of each of these options. In addition, they were told that their infants will be included in this study and how to give the drugs, what to watch on their infants and what are the possible side effects or signs that may appear on their infants and when to consult for re-checking.

Informed Consent were taken from all parents whose infants participated in the present study, in addition ethical approval was obtained from the local national ethical committee of the Arab board of Dermatology and Venereology.

\section{Dose of propranolol and method of application of timolol}

Oral propranolol in a dose of $1 \mathrm{mg} / \mathrm{kg} / \mathrm{dose}$ grinded and dissolved in water was taken in two divided doses and topical timolol $0.5 \%$ solution (eye drop) two time per a day were applied at a dose of 1 drop for each $1 \mathrm{~cm}^{2}$ surface area of the lesion started after taking a photograph as a baseline and in each visit by camera of 8 Mega.

In addition, parents were educated about signs of hypoglycemia and encourage them to feed the infant before each dose and do not administer before bedtime without feeding, and first dose was taken in dermatology department under our observation.
The infants were checked monthly for 4 months. In each visit; the hemangiomas were examined regarding response to treatment (changes in color, size, consistency, and firmness of the hemangioma), body weight was measured to adjust the dose of propranolol side effects of propranolol was assessed (examination of cardiopulmonary system, heart rate, blood pressure, respiratory rates were measured in each visit).

\section{Evaluation the response to treatment}

The response to treatment was assessed clinically by interval at $4^{\text {th }}$ weeks, 8 thweeks, $12^{\text {th }}$ weeks and at end of $16^{\text {th }}$ weeks. The results were interpreted by two methods:

Hemangioma score [5]: This scoring system consists from five components: color, surface consistency, firmness, depth by ultrasound (not done so all lesions were scored 0 ) and organ involvement. In each visit we score the lesions and calculate the percentage of reduction in hemangioma score. The responses were categorized in to four groups as the following:

- Poor response: if the reduction in hemangioma score range from $25 \%$ or less regression).

- Fair response: reduction in hemangioma score range from $26 \%-50 \%$.

- Good response: reduction in hemangioma score range from $51 \%-75 \%$.

- Excellent response: reduction in hemangioma score range from $76 \%-100 \%$.

Visual analogue scale [6]: The results were categorized into three classes compared with the baseline photographs by 2 independent dermatologists.

These are:

- class 1: ineffective, i.e. the lesion continues to grow.

- class 2: controlled growth, i.e. the lesion stopped growing and showed no significant change in size or color.

- class 3: promoted regression, i.e. the lesion became smaller, and lighter in color.

The regression rate represents the percentage of cases in class 3 results, while the efficacy rate represented the percentage of cases in class 2 and class 3 results.

\section{Statistical analysis}

Results were presented in numbers, percentages, mean values $\pm \mathrm{SD}$, and ranges. Data statistically analyzed by using KruskalWallis analysis of variance test by the statistical package for social sciences (SPSS software v.20) and statistical significance was set at $\mathrm{P}<0.05$. 


\begin{tabular}{llc}
\hline Table 1. Hemangioma score [5] & \\
\hline Component & Quality & Score \\
\hline Color of & Bright Red & 2 \\
hemangioma & Pale & 1 \\
& Skin Color & 0 \\
\hline Surface & Markedly Raised & 2 \\
consistency & Raised & 1 \\
\hline Firmness & Flat & 0 \\
& Firm & 2 \\
\hline Depth if & Softer & 1 \\
ultrasound is & Not Firm or Much Softer & 0 \\
performed; & Maximal (90-100\%) & 2 \\
otherwise 0 & Less (50-89\%) & 1 \\
\hline Organ & No Depth or Less Deep (<50\%) & 0 \\
involvement & Functional Limitation & 7 \\
\hline Total score & Impending Functional Limitation & 4 \\
\hline
\end{tabular}

\section{RESULTS}

\section{Demographic data}

Patients' demographic data was summarized in Table 2. There were 23 infants 22 female and 1male, their ages range between 1-12 months, the mean of their age was $4.26 \pm 1.76$ months. About 34 lesions were located at different parts of their bodies, these were 11 superficial (32.4\%) type, 18 mixed (52.9\%) and 5 ulcerative type $(14.7 \%)$. None of these infants received any treatment for hemangioma before.

\begin{tabular}{|c|c|c|c|}
\hline Category & Subcategory & Number & $\%$ \\
\hline \multirow[b]{2}{*}{ Age } & Less Than Six Months & 31 & 91.2 \\
\hline & $\begin{array}{l}\text { More Than Six Months Up to } \\
\text { One Year }\end{array}$ & 3 & 8.8 \\
\hline \multirow{2}{*}{ Sex } & Male & 1 & 2.9 \\
\hline & Female & 22 & 97.1 \\
\hline \multirow{3}{*}{$\begin{array}{l}\text { Type of } \\
\text { Hemangioma }\end{array}$} & Superficial & 11 & 32.4 \\
\hline & Mixed & 18 & 52.9 \\
\hline & Ulcerative & 5 & 14.7 \\
\hline \multirow{4}{*}{ Site } & Head and Neck & 20 & 58.8 \\
\hline & Trunk & 6 & 17.6 \\
\hline & Extremities & 7 & 20.6 \\
\hline & Genitalia & 1 & 2.9 \\
\hline
\end{tabular}

Response to treatment according hemangioma score system.

Reduction in the mean score of hemangioma in subsequent visits throughout the study

Statistical analysis showed that treatment of infantile hemangioma with combination of oral propranolol and topical timolol achieved responses in $100 \%$ of this series (34/34). The mean of hemangioma score before treatment was $5.73 \pm 1.33$, and it was reduced to $0.79 \pm 1.008$ at end of trial. These results indicated that involution of hemangioma was statistically significant $(\mathrm{p}<0.05)$ (Table 3$)$.

Table 3. Reduction in the mean score of hemangioma at 4, 8, 12 and end of 16 weeks of treatment

\begin{tabular}{lc}
\hline Duration & Mean of score \pm SD \\
\hline Base line & $5.73 \pm 1.33$ \\
\hline 4 weeks & $2.91 \pm 0.83$ \\
\hline 8 weeks & $1.97 \pm 1.26$ \\
12 weeks & $1.23 \pm 1.18$ \\
\hline 16 weeks & $0.79 \pm 1.008$ \\
\hline$P$ value $<0.05$ &
\end{tabular}

Figure 1. Hemangioma score before treatment, at 4 weeks, 8 weeks, 12 weeks and at the end of 16 weeks

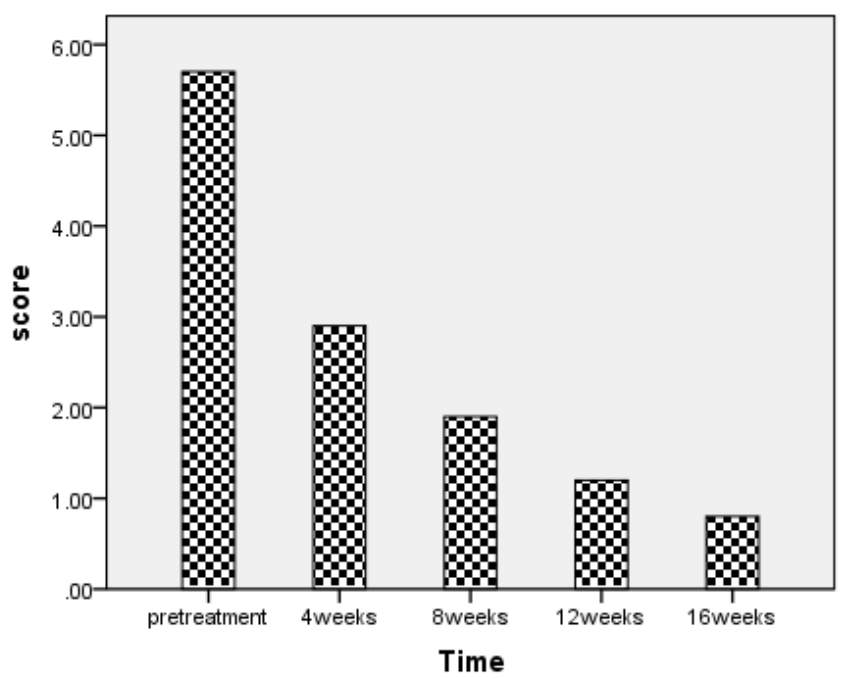

Early clinical response occurred within the first 4 weeks of treatment as 6 lesions (17.6\%) showed good response, 26 lesions (76.5\%) showed fair response, 2 lesions (5.9\%) showed poor response and none of them show excellent response. During the following clinical evaluation visits, a significant continuous reduction in scores occurred.

At end of 16 weeks, out 34 lesions of hemangioma, 28 (82.4\%) lesions showed excellent response, two (5.9\%) showed good response, four $(11.8 \%)$ showed fair response and none of the lesions showed poor response (Table 4). 
Topical Timolol and Oral Propranolol in Infantile Hemangioma

\begin{tabular}{|c|c|c|c|c|c|c|c|c|}
\hline \multirow{2}{*}{ Response } & \multicolumn{2}{|c|}{4 weeks } & \multicolumn{2}{|c|}{8 weeks } & \multicolumn{2}{|c|}{12 weeks } & \multicolumn{2}{|c|}{16 weeks } \\
\hline & $n$ & $\%$ & $n$ & $\%$ & $n$ & $\%$ & $n$ & $\%$ \\
\hline Fair & 26 & 76.5 & 18 & 52.9 & 7 & 20.6 & 4 & 11.8 \\
\hline Good & 6 & 17.6 & 6 & 17.6 & 7 & 20.6 & 2 & 5.9 \\
\hline
\end{tabular}

In this study; the average period of treatment was 3 months $(2-4$ months) where complete regression $($ score $=0)$ was observed in 8 lesions (23.52\%) after 2 months of treatment, 5 lesions (14.7\%) after 3 months of treatment and 4 lesions (11.76\%) showed complete regression at end of 4 months of treatment, so total lesions which showed complete regression were 17 lesions (50\%) as showed in Table 5.

Table 5. Complete regression of infantile hemangioma throughout the study

\begin{tabular}{lcc}
\hline Visits & Number of Complete Regression & $\%$ \\
\hline 4 weeks & - & - \\
8 weeks & 8 & 23.52 \\
12 weeks & 5 & 14.7 \\
16 weeks & 4 & 11.76 \\
Total & $\mathbf{1 7}$ & $\mathbf{5 0}$ \\
\hline
\end{tabular}

\section{Response to treatment according to types of the hemangioma}

At end of 4 weeks ulcerative hemangioma showed 59.45\% reduction in their score, the superficial hemangioma showed $50.65 \%$ while mixed hemangioma showed only $44.40 \%$ reduction in their score.

Ulcerative hemangioma showed rapid reduction in score from the first month of treatment and start to change to skin color from center of ulcer to the periphery of the lesion.
At end of 16 weeks superficial hemangioma showed $100 \%$ (excellent response) reduction in their score, while the ulcerative hemangioma showed $94.7 \%$ (excellent response)reduction in their score and mixed hemangioma showed only $76.7 \%$ reduction in their scores(good response). There is no significant difference in response to treatment between ulcerative and superficial types at end of 16 weeks of treatment, while there is significant statistical difference between the two former types and the mixed type $(\mathrm{p}<0.05)$ (Table 6).

Table 6. Response to treatment regarding the types of hemangioma (percentage of reduction in mean of score)

\begin{tabular}{lccc}
\hline Visits & Superficial \% & Mixed \% & Ulcerative \% \\
\hline 4 weeks & 50.65 & 44.40 & 59.45 \\
8 weeks & 74.34 & 52.88 & 89.18 \\
12 weeks & 96.08 & 65.08 & 91.89 \\
16 weeks & 100 & $76.7^{*}$ & 94.7 \\
\hline
\end{tabular}

*Significant difference $p<0.05$

At 8 weeks Complete regression was shown in 8 of lesions; 5 of them were superficial type ( $45 \%$ of superficial lesions which were 11 lesions) and 3 lesions were ulcerative type (60\% of lesion which were 5). And at 12 weeks another 4 lesions of superficial type were showed complete resolution, and one of lesion from mixed type was showed complete regression (5.5\% of mixed type which were 18 lesions). At end of 16 weeks all superficial lesions were showed complete regression (100\%), and another two lesions of mixed type showed complete regression $(16.6 \%$ from mixed type which were 18 lesion) (Table 7).

Table 7. Complete regression regarding types of hemangioma

\begin{tabular}{|c|c|c|c|c|c|c|c|c|c|}
\hline \multirow{3}{*}{ Visits } & \multicolumn{9}{|c|}{ Types of Hemangioma } \\
\hline & \multicolumn{3}{|c|}{ Superficial } & \multicolumn{3}{|c|}{ Mixed } & \multicolumn{3}{|c|}{ Ulcerative } \\
\hline & $\begin{array}{c}\text { Total } \\
\mathbf{n}\end{array}$ & $\begin{array}{c}\text { Regression } \\
\mathrm{n}\end{array}$ & $\%$ & $\begin{array}{c}\text { Total } \\
\mathbf{n}\end{array}$ & $\begin{array}{c}\text { Regression } \\
n\end{array}$ & $\%$ & $\begin{array}{c}\text { Total } \\
\mathbf{n}\end{array}$ & $\begin{array}{c}\text { Regression } \\
\mathrm{n}\end{array}$ & $\%$ \\
\hline 4 weeks & 11 & - & - & 18 & - & - & 5 & - & - \\
\hline 8 weeks & 11 & 5 & 45.5 & 18 & - & - & 5 & 3 & 60 \\
\hline 16 weeks & 11 & 2 & 18.2 & 18 & 2 & 11.1 & 5 & - & - \\
\hline Total & 11 & 11 & 100 & 18 & 3 & 16.6 & 5 & 3 & 60 \\
\hline
\end{tabular}




\section{Response to treatment according to the age of infants}

There is no statistically significant between the response to treatment in the infant whose ages were less than 6 months and those whose ages were more than 6 months $(\mathrm{P}=0.16)$ (Table 8).

\section{Response to treatment according visual analogue scale}

Response to treatment was assessed by two independent dermatologists who classified the lesions according VAS in each visits: in the first visit 4 lesions (11.8) were classified as class 1 (ineffective, i.e. the lesion continued to grow), 9 lesion (26.5\%) were classified as class 2 (controlled growth, i.e. the lesion stopped growing and showed no significant change in size or color) and 21 lesions (61.8\%) were classified as class 3 (promoted regression, i.e. the lesion became smaller and lighter in color). At the end of 16 weeks of treatment none of the lesions were classified as class 1, 2 lesions (5.9\%) were classified as class 2 and 32 lesions (94.1\%) were classified as class 3 which is highly statistically significant (Table 9) (Picture 1 and 2).

The regression rate is $94.1 \%$ (percentage of cases with class 3 ). The efficacy rate is $100 \%$ (percentage of cases with class 2 and class 3).

\section{Satisfaction to treatment}

At end of 16 weeks of treatment the satisfaction of infants' parents assessed to each lesion separately; it was about $27(79.4 \%)$ were fully satisfied, $5(14.7 \%)$ partially satisfied and $2(5.9 \%)$ not satisfied to treatment (Table 10).

Table 8. Response to treatment in relation to ages of infants

\begin{tabular}{|c|c|c|c|c|c|c|c|c|}
\hline \multirow{3}{*}{ Age } & \multicolumn{8}{|c|}{ Visits } \\
\hline & \multicolumn{2}{|c|}{4 weeks } & \multicolumn{2}{|c|}{8 weeks } & \multicolumn{2}{|c|}{12 weeks } & \multicolumn{2}{|c|}{16 weeks } \\
\hline & $\mathbf{n}$ & $\%$ & $\mathbf{n}$ & $\%$ & $\mathbf{n}$ & $\%$ & $\mathbf{n}$ & $\%$ \\
\hline Less than six months & 31 & 48.4 & 31 & 65.1 & 31 & 77.9 & 31 & 85.6 \\
\hline More than six months & 3 & 53.3 & 3 & 77.8 & 3 & 94.4 & 3 & 100 \\
\hline
\end{tabular}

Table 9. Response to treatment assessed by visual analogue scale

\begin{tabular}{|c|c|c|c|c|c|c|c|c|}
\hline \multirow{2}{*}{ Visits } & \multicolumn{2}{|c|}{$\begin{array}{c}\text { Class } 1 \\
\text { Ineffective } \\
\end{array}$} & \multicolumn{2}{|c|}{$\begin{array}{c}\text { Class } 2 \\
\text { Stopped Growth }\end{array}$} & \multicolumn{2}{|c|}{$\begin{array}{c}\text { Class } 3 \\
\text { Promoted Regression }\end{array}$} & \multicolumn{2}{|c|}{ Total } \\
\hline & $n$ & $\%$ & $\mathrm{n}$ & $\%$ & $n$ & $\%$ & $n$ & $\%$ \\
\hline 4 weeks & 4 & 11.8 & 9 & 26.5 & 21 & 61.8 & 34 & 100 \\
\hline 8 weeks & 0 & 0 & 9 & 26.5 & 25 & 73.5 & 34 & 100 \\
\hline 16 weeks & 0 & 0 & 2 & 5.9 & 32 & 94.1 & 34 & 100 \\
\hline
\end{tabular}

Table 10. Satisfaction to treatment

\begin{tabular}{lcc}
\hline Satisfaction of Parents to Treatment & $\mathbf{n}$ & $\%$ \\
\hline Not Satisfied & 2 & 5.9 \\
Partially Satisfied & 5 & 14.7 \\
Fully Satisfied & 27 & 79.4 \\
Total & 34 & 100 \\
\hline
\end{tabular}

Side effects to treatment: Out of 23 patients; 2 patients $(8.6 \%)$ developed side effects, including agitation in one infants and the other developed cold extremities. None of lesions showed evidence of recurrence after cessation of treatment for 4-12 months of follow up.

\section{DISCUSSION}

Infantile hemangioma $[\mathrm{IH}]$ is the most common benign vascular tumors in infancy [1]. It is a cause of parental discomfort and anxiety. It has un predictable outcome regarding their size, cosmetic disfigurement and other complications, so the treatment of $\mathrm{IH}$ is frequently indicated in many cases [2]. In our study the indications for treatment were a fearing from disfigurement, threatened interference with vital functions and skin ulcerations.

Many treatment modalities were used for IH but none of them is FDA approved except propranolol [3], despite of this truth, the proper dosing, mode of administration and long-term outcome still not standardized. 


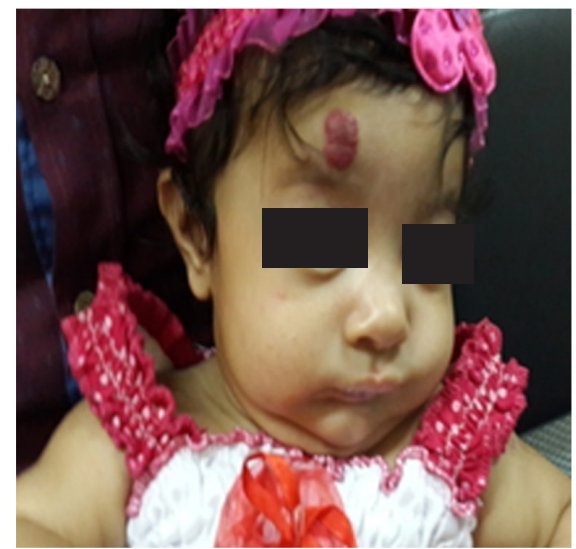

Superficial hemangioma before

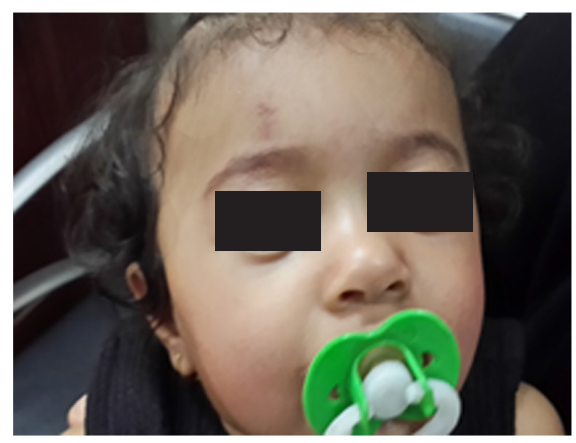

After 12 weeks of treatment

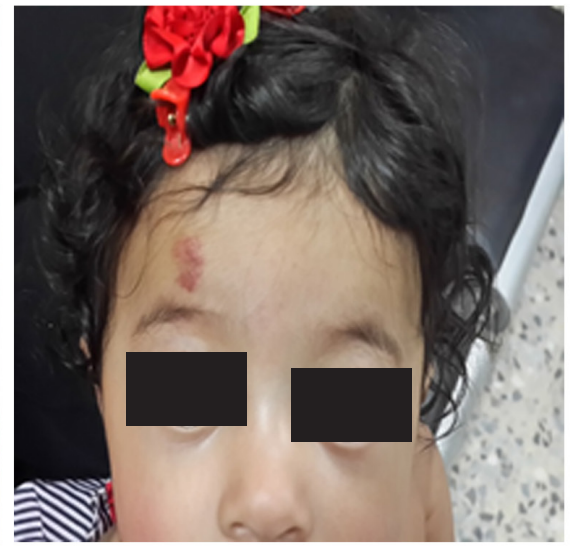

After 4 weeks of treatment

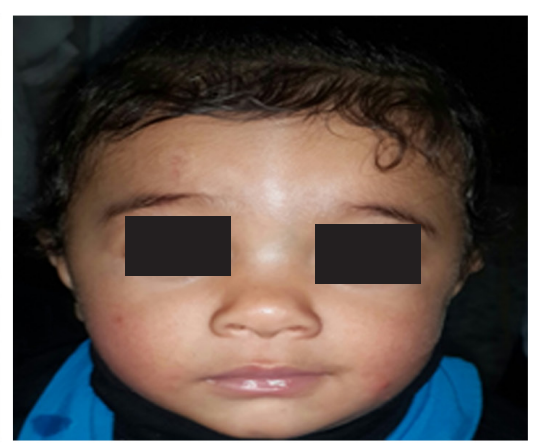

After 16 weeks of treatment

Picture 1. Appearance of superficial hemangioma at fourth, $12^{\text {th }}$, and 16 th weeks

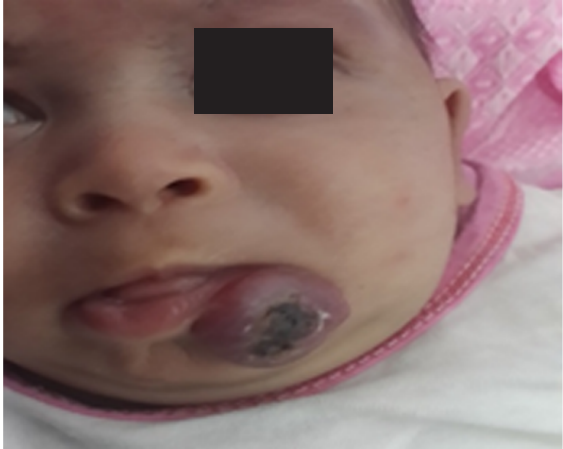

Ulcerative IH before treatment

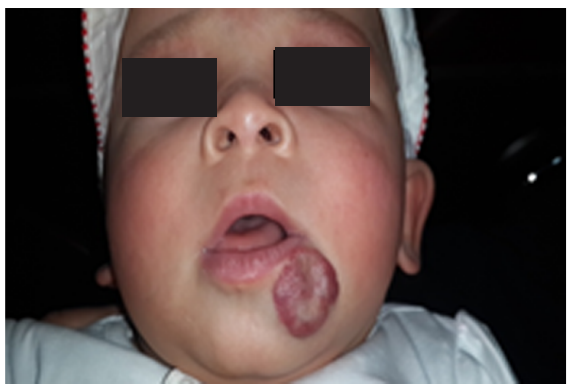

After 12 weeks of treatment

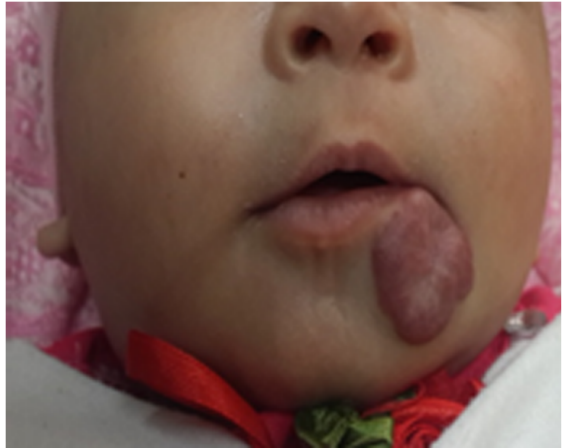

After 4weeks of treatment

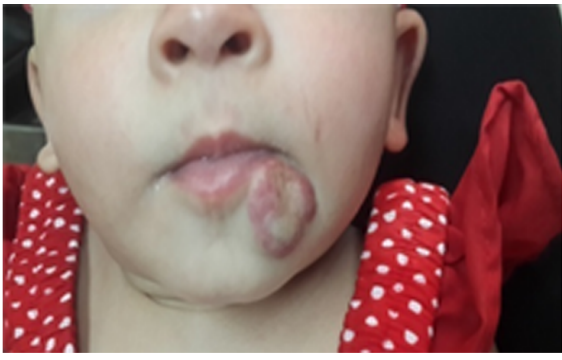

After 16 weeks of treatment

Picture 2. Appearance of ulcerative hemangioma at fourth, $12^{\text {th }}$, and $16^{\text {th }}$ weeks of treatment 
The average period of treatment of IH with propranolol was about 6.4 months [range 1 week-15 months] in a systematic review of 1264 child in 41 studies [6]. The major obstacles to treatment with systemic propranolol was the long duration, which made the compliance of parent to treatment was poor, introduction of other modality of treatment with systemic propranolol may shorten the duration of treatment of $\mathrm{IH}$, ultimately improve the outcome of treated hemangioma and it may increase of infant's parent's compliance to drug.

Topical timolol which is $4-10$ times as potent as propranolol [4], added to systemic propranolol in treatment of $\mathrm{IH}$ in this study to achieve the above-mentioned issue.

The age of infants who were included in this study was less than 12 months. This was done in order to solidify the results of the study, since hemangiomas has their maximum rate of growth during the first year of life after which it starts to involute during the next few years [1], that is why the present study is conducted to include infants in their first year of life, i:e, where $I H$ is in it is proliferative phase and any regression will be attributed to the effect of drug rather than to the natural history of hemangioma.

In this study; the average period of treatment was 3 months [2-4 months] which is shorter than that of the above-mentioned studies. At end the of 4 months of combined therapy $82.4 \%$ of lesions showed excellent response [76-100\% reduction in their score] which is higher than that reported in other study which use systemic propranolol alone where the excellent response was $76.7 \%$ [8].

On the other hand, the regression and the efficacy rates in this study was $94.1 \%, 100 \%$, respectively. These results were higher than a similar study done in China which, followed VAS and use timolol alone. The regression rate in the Chinese study was $56.4 \%$ and the efficacy rate was $92.1 \%$ despite the frequency of application was three times daily [6] instead of twice application which was used in the present study.

Ulceration represented the most common complication of $\mathrm{IH}$ and it occurs in up to $10 \%$ of them [9]. As resolution may not occur spontaneously for several months, so a physician should take an active approach to treating the ulcers [2]. Oral propranolol has been used successfully in this setting [10,11], it showed gradual re epithelization of ulceration [8] although not all ulcerated hemangiomas respond and some may even worsen[12]. In the present study where combined treatment were used, the fastest types of hemangioma responding to treatment was the ulcerative type, where the percentage of reduction in their scores at end of 4 weeks of treatment was $59.45 \%$ while the superficial hemangioma showed $50.65 \%$ and mixed hemangioma showed only $44.40 \%$ reduction in their score in same period of treatment.

Ulcerative hemangioma showed rapid reduction in score from the first month of treatment and start to change to skin color from the center of ulcer to the periphery of the lesions, this finding may be due to rapid and direct action of topical timolol solution which may result in enhancement of the re -epithelization of ulcerative lesion,this action will strengthen the effect of systemic propranolol that has been mentioned above, so lead to faster and more better outcome than the using any one of these drugs separately in previous studies $[8,13]$. Despite systemic absorption of topical timolol has been reported [14] but it was low, these make the caution from using of topical timolol with oral propranolol is less need except for large $\mathrm{IH}$ or large ulcerative one.

At end of the study no significant difference between percentage of reduction in the score of ulcerative and superficial types which were showed $94.7 \%$ and $100 \%$ respectively ; this may be due to return most of ulcerative surface of hemangioma to normal skin with time where the effect of topical timolol is going to be similar in two conditions, in addition to that the mixed type of hemangioma showed only $76.7 \%$ percentage of reduction in their sore ,this is may be due to deep component of this type where the direct action of Timolol is supposed to be less than the ulcerative and superficial type.

Moreover, this study showed that all superficial hemangiomas were regressed completely leaving only trace or just minimal telangiectasia, while $60 \%$ of ulcerative type showed complete regression, $16.6 \%$ only showed complete regression in mixed type.

Complete regression was reported in $50 \%$ of the lesions at end of this study (i.e. 16 weeks), which is higher than other study that used oral propranolol alone where complete regression was reported only in $14.5 \%$ despite longer duration of treatment which was 6 months as average [15].

Complete regression in superficial types of $\mathrm{IH}$ in the present study was $100 \%$ at end of 4 months of treatment of combined therapy. These results are much higher than that of other study which used only topical timolol for the same period where complete regression was only $11.88 \%$ [6].

There was no statistically significant difference between the response to treatment in the infant whose ages were less than 6 months and those who were older, this result is consistent with that of other study [8] where the treatment started during the first year of life.

In this study none of patients developed serious side effects that was reported in other studies $[16,17,7]$. This probably attributed to the information that were given by researcher to the parents regarding methods of drug intake and warning signs of any possible side effects and method of avoiding them, in addition to strict follow up of patients directly or by conducting their parents by telephone.

On the other hand, none of the lesions in present study showed evidence of recurrence after cessation of treatment during follow up period 4-12 months, in contrast to that of other studies which reported recurrence of $\mathrm{IH}$ after cessation of treatment $[1,15.18]$ this is probably due to double effects of both these beta blockers on $\mathrm{IH}$. 
Approximately $94 \%$ of infant's parent were fully or partially satisfied to results of treatment, which is considered as another indicator for efficacy of treatment.

Lastly, fear of parents from using oral propranolol which is a well-known beta blocker commonly used for cardiovascular diseases, limit or decrease the number of patients who were enrolled in this study.

In conclusion, combined topical Timolol $0.5 \%$ solution and oral propranolol in a dose $1 \mathrm{mg} / \mathrm{kg} /$ dose in equal two divided doses after feeding seems to be a well-tolerated, safe treatment option with excellent to good responses in treatment of IH. Although, this combination is effective treatment for all types of hemangioma, but it showed more effectiveness in superficial and ulcerative type in average period of treatment about 3 months. Combined therapy is recommended as an alternative to systemic $\beta$-blockers or topical timolol alone to shorten the duration of treatment thereby decease side effects of drug and improved the compliance of infant' parents for continuous the treatment and to reach to better outcome.

Conflict of Interests: The authors declare that they have no conflict of interest.

Financial Disclosure: No financial support was received.

\section{REFERENCE}

1. Haggstrom AN, Garzon MC. Infantile hemangioma. in Dermatology, Editors, Bolognia JL, Jorizzo JL, Shchaffer JV. $3^{\text {rd }}$ ed. Saunders-Elsevier; inc.2012;103,1691-1707.

2. James WD, Berger TG, Elston DM. Dermal and Subcutaneous Tumors, in: Andrew Diseases of The Skin Clinical Dermatology. $11^{\text {th }}$ ed. Elsevier Inc. 2011;28.574-619.

3. FDA OKs Propranolol Hydrochloride for Infantile Hemangioma. Medscape. Mar 17, 2014 http://www.medscape.com/viewarticle/822115 [accessed at 26/11/2016].

4. McMahon P, Oza V, Frieden IJ. Topical timolol for infantile hemangiomas: putting a note of caution in 'cautiously optimistic'. Pediatr Dermatol 2012;29:127-30.
5. Talaal AA, Elbasiouny MS, Elgendy DS, Elwakil TF. Propranolol treatment of infantile hemangioma: clinical and radiological evaluations. J Pediatr Surg 2012;47:707-14.

6. Yu L, Li S, Su B, et al Treatment of superficial infantile hemangiomas with timolol: Evaluation of shortterm efficacy and safety in infants. J Exp Therap Med. 2013;6:2-7.

7. Marqueling AL, Oza V, Frieden IJ, Puttgen KB. Propranolol and infantile hemangiomas four years later: a systematic review. Pediatr Dermatol 2013;30:182-91.

8. Al-Hamdi K, Zainab Al-Khaledy Z, Al-Amiry A. Clinical evaluation of the oral propranolol efficacy and safety in the treatment of infantile hemangioma. Int J Med Pharm Sci 2015;5:85-98.

9. Chamlin SL, Haggstrom AN, Drolet BA, et al. Prospective study of ulcerated hemangiomas. J Pediatr. 2007;151:684-9.

10. Sans V, de la Roque ED, Berge J, et al. Propranolol for severe infantile hemangiomas: follow-up report. Pediatrics. 2009;124:e423-31.

11. McGee P, Miller S, Black C, Hoey S. Propranolol for infantile hemangioma: A review of current Dosing Regime in a Regional Paediatric Hospital. Ulster Med J 2013:8216-20.

12. Michel JL, Patural H. Response to oral propranolol therapy for ulcerated hemangiomas in infancy Arch Pediatr. 2009;16:1565-8.

13. Al-Hazim M, Al-Saady SJJ. Topical timolol in treatment of infantile hemangioma, thesis was submitted in partial fulfillment for certification by the Arab Board of medical Specialization in dermatology and venereology 2014

14. Weibel L, Barysch MJ, Scheer HS, et al. Topical Timolol for infantile hemangiomas: Evidence for efficacy and degree of systemic Absorption. Pediatr Dermatol 2016;33:184-90.

15. Schupp CJ, Kleber JB. Propranolol therapy in 55 infants with Infantile hemangioma: Dosage, duration, adverse effects, and outcome. Pediatr Dermatol. 2011:28:640-4.

16. Lawley LP, Siegfried E, Todd JL. Propranolol treatment for hemangioma of infancy: risks and recommendations. Pediatr Dermatol. 2009;26:61014.

17. Frieden IJ, Drolet BA. Propranolol for infantile hemangiomas: promise, peril, pathogenesis. Pediatr Dermatol. 2009;26:642-4.

18. Tan S, Itinteang T, Leadbitter P. Low-dose propranolol for infantile hemangioma. J Plast Reconstr Aesthet Surg 2010;2: 142-6. 